\title{
Negotiating Feelings and Multiculturalism: Towards a Sociological Study on Cultural Shock and Intercultural Communication
}

\author{
Josinta Zinia \\ Assistant Professor, Department of Sociology, \\ Bangladesh University of Professionals \\ Tahmina Sultana \\ Lecturer, Department of Management, \\ Bangladesh University of Professionals \\ Muhammad Kawsar Mahmud \\ Section Officer, Public Relation, Information and Publication office, \\ Bangladesh University of Professionals
}

\begin{abstract}
Cultural shock is an anxiety produced when a person moves from a familiar culture to an entirely different cultural or social environment. This paper is an attempt to describe how Bangladeshi students experience cultural shock while studying in different foreign universities. The main purpose of this study is to examine perceptions of cultural shocks among the Bangladeshi students and its psychological impact on them. This study follows quantitative research methodology. This study reveals that there is a considerable cultural shock exists among the students staying abroad. These shocks include but not limited to food complicacy, financial intricacy, environmental complexity, a new pattern of dress-up, and language barrier.
\end{abstract}

Keywords: Culture, Cultural Shock, Acceptance.

\section{INTRODUCTION}

In this era of globalization, the higher education of different developed countries brings the learners from diverseculture and creates a heterogeneous environment (Chinnammai, 2005). Cultural activities of the societies in this world differ from each other (Veras \& Veras, 2011). These learners on many occasions find a different way of living, different language, different kinds of festivals, clothing, eating habit and religious traditions. Sometimes the attitudes of people around them and the surroundings are no longer familiar. In this regards, there remains a cultural shock while understanding and adapting to these changes. Sometimes it creates psychological and mental disillusion, inferiority complex, or even physical sickness (Naeem, Nadeem \& Khan, 2015). For instance, the change of food habit or unavailability of native food might be risky to live a healthy life.

A number of Bangladeshi students have been migrated each yearforpursuing higher education. According to the latest data from UNESCO, more than 33,000 students are taking overseas education while 15,700 were in 2007 and 7169 were in 1999. According to UNESCO, Malaysia, the United States of America, the United Kingdom, Australia, Germany, and Canada are the top destinations for Bangladeshi students. Among the 33,139 students who went abroad in 2016, $20 \%$ enrolled in Malaysian universities, $16 \%$ in US universities, $14 \%$ in UK universities, 13\% in 
Australian universities, $6 \%$ in German, and 5\% in Canadian universities. Not all students stay back, however. Some do return home in hopes of contributing to the development of Bangladesh (Dhaka tribune, 2018). Bangladeshi students go abroad for honors', masters or $\mathrm{PhDs}$ on different subjects. Culture varies country to country,the way of living, language, different kinds of festivals, clothes, eating habit, religions, traditions etc. (Banglapedia, 2004). When a student studies in abroad, daily routine, culture, and the attitudes of people around him are no longer familiar. Cultural shock has a severe effect on the students those results in many more unexpected events. A Bangalore student commits suicide in German since he has been harassed by his senior. He was fed up on them. Before death, he wants to return the home (The Times of India, 2013). Muslim students face problem to put on the headscarf. Once someone shares a phone number in her Face book, she received a hate message. In 2011, France became the first European country to ban the full-face Islamic veil in public places, while alternatives such as hijabs, which cover the head and hair, remained legal (BBC, 2018). A student moved to Australia from India's Gujarat state in 2014. He was a qualified physiotherapist by profession andpursuing Masters on Public Health. She wants to earn some money.She needs to register to do something but could not do easily owing to overseas health professionals (Sarwal, 2017). A number of foreign students are enrolling in the USA for higher education. It has found from a study in 2011-2012 that the number of international students in the USA increased by $6.5 \%$ over the last year to a record high of 764,495 students.56\% students came from only five countries namely China, India, South Korea, Saudi Arabia and Canada. Studying and writing in a foreign academic language is difficult enough, but it is often the classroom dynamic that is most daunting to foreign students. From that study, it has noticed that $40 \%$ of foreign students in the US have no close friends on campus (Niekerk, 2012).

The phrase culture shock has been attributed to the anthropologist KalervoOberg, who in an article in 1960 used it to illustrate how people react to strange or unfamiliar places. In the book (Ward, Bochner and Furnham, 2001) it is alluded that there is no doubt that it reflects some of the feelings and experiences of travelers who suddenly find themselves in new, strange, or unfamiliar places. The unknown can be an uncomfortable and at times terrifying experience. However, the use of the word "shock" places too much emphasis on the threatening circumstances of contact with novel situations, without acknowledging that such experiences may also have beneficial consequences for the participants. This led us to contend that over the years "culture shock" has become a widely misused term, both in popular language as well as in cross-cultural psychology. This article will identify some of the empirical conditions under which travel across cultures can be stressful, offer a theoretical explanation for such an outcome, and provide a brief account of the strategies that can be used to reduce contactinduced stress. As such, we will restrict ourselves to the "culture shock" of between-society culture contact, that is, the psychology of the traveler or sojourner who ventures across cultures.

However, once the causes are identified, it will be easier for the students to change the approach and adapt tothe new culture. It is obviously important that these sojourners adapt to the new culture rapidly in order that they can operate doings effectively. Various causes of cultural shock will be identified through this study that Bangladeshi students face in abroad. This paper will give them an insightful knowledge on sorts of cultural barriers and the way to adaptin the new milieu.

\section{CULTURAL SHOCK: FROM THEORETICAL PERSPECTIVES IN SOCIOLOGY}

Oberg's (1954) anthropological discussion of culture shock recognized four phases of social modification that portray the procedure that individuals experience when they are adjusting to 
another social condition. Monitoring these stages can enable consultants to recognize mediation focuses and methodologies for helping understudies. It is valuable to think about this procedure of modification when working with global understudies at all phases of their U.S. scholarly professions and to comprehend that the time it takes every understudy to travel through the stages will rely upon how an individual understudy is influenced by the two components talked about above: social separation and identity.

\section{The Honeymoon Stage}

This stage is an energizing time when people investigate new societies, however inclusion in the new culture is shallow and traveler like. Understudies in this stage are eager to be in another nation and may disregard their examinations as they investigate their new condition. They will appear to be upbeat and balanced and may not envision challenges ahead. At this stage, counselors can get ready understudies for what they may involvement and make open doors for them to start taking in the new social principles as fast as could reasonably be expected. It might guarantee understudies that everybody encounters culture shock and that a guide will be accessible to help them when issues emerge.

\section{The Cultural Shock Stage}

Stage two is portrayed by aggravation and dissatisfaction with the contrasts between the home culture and new culture. Social contrasts in correspondence styles and enthusiastic articulation can elucidate the issue and make it harder to perceive understudies having issues. Consultants may think that it's hard to connect with understudies in this stage. Guo (2016) gives phenomenal methodologies to building trust and drawing in global understudies. Now and again, counselors may need to guide understudies to worldwide understudy administrations or advising assets on grounds. Counsels ought to likewise keep on providing open doors for global understudies to communicate with local understudies to expand their social encounters, enabling them to move to the following stage.

\section{The Gradual Adjustment Stage}

In organize three, the steady change arranges, people start to take in more about and comprehend their host culture. They additionally have a tendency to romanticize their home culture, and they may at first ridicule esteems and practices that are unique in relation to what they are utilized to. Be that as it may, as they gain a more profound comprehension of the new culture, they additionally gain a more profound regard for their host nation. This procedure is slow and longer than alternate stages, and it might contain many good and bad times. Understudies need to learn new systems for managing pressure and depression without the help structures they are utilized to at home. Counselors can perceive understudies in this stage since they will need to discuss the distinctions they have seen and share tales about their encounters. Tuning in to understudies' worries and sympathizing with their endeavors to comprehend can enable them to adjust.

\section{The Adaptation Stage}

In the long run, most people who invest a significant length of energy in another culture will achieve the fourth stage, that of acknowledgment and adjustment. They are never again adversely influenced by contrasts in culture and can take an interest in social associations without trouble. Understudies who have achieved this stage can help consultants who are working with understudies who are as yet encountering society stun by going about as envoys or associate instructors.

Consultants should know about worldwide understudies' level of change in accordance with their host culture. Culture stun will influence their conduct and whether they look for help 
when it is required. Guides ought to urge worldwide understudies to have however much social collaboration with local understudies as could be expected and can help create projects and occasions to encourage such associations. Global understudies regularly search out others from their own way of life for help in a new domain. Joseph and Baker (2012) found that Caribbean understudies contemplating in the U.S. announced inclination less culture stun when they had different understudies from their nation of origin to make a feeling of network. Be that as it may, depending on a network of individuals from their own particular culture can make understudies stay in their usual range of familiarity, keeping them from getting to be acculturated to their new condition. The more global understudies discover events to communicate with local understudies and others in the host network, the more rapidly they will overcome the obstacle of culture stun and the more achievement they will have as worldwide understudies. Figuring out how to perceive the phases of culture stun will enable consultants to help understudies with traveling through the way toward adjusting to their new condition.

\section{CONCEPTUAL FRAMEWORK}

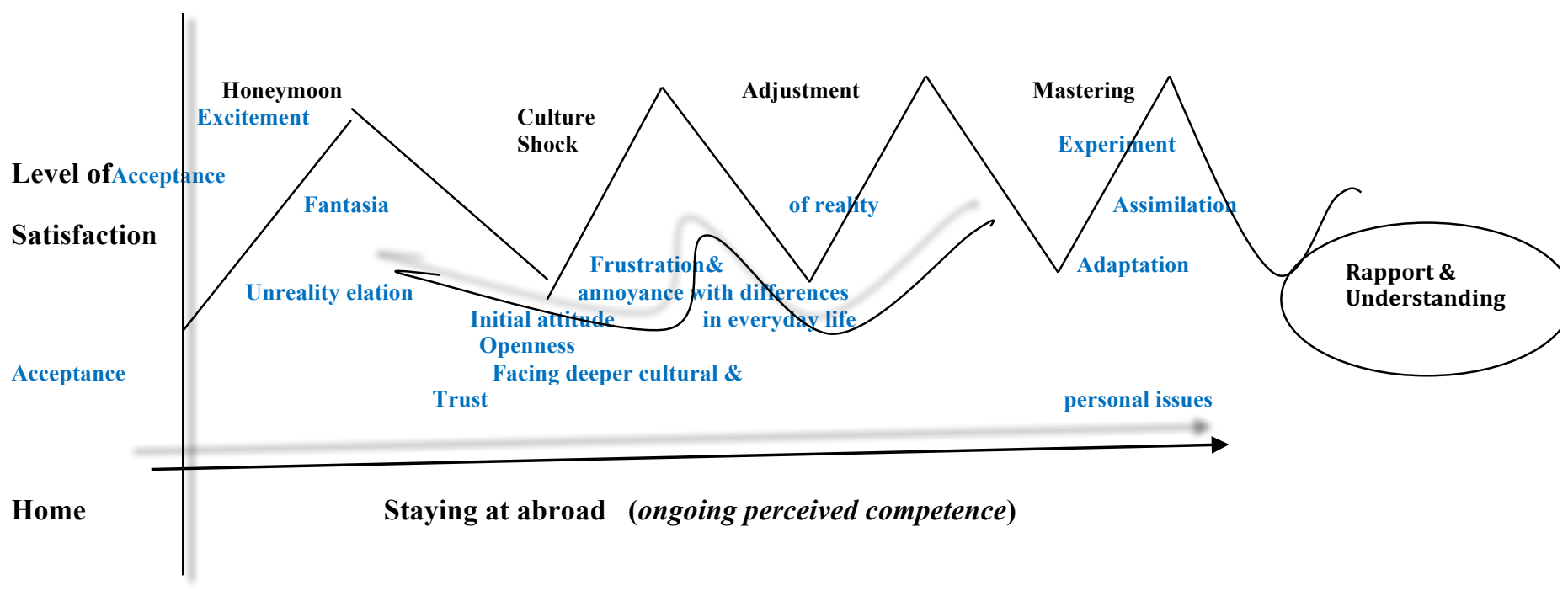

Source:Prepared by authors' survey data

\section{LITERATURE REVIEW}

There are many avalanches of literatures on culture shock and its various psychological impacts on people. Many books, research articles and reports have been written on this topic. The kinds of literature have discussed different aspects of cultural shocks. In the literature, it has seen that someone in the host country confronts different barriers like the language barrier, food complicacy, understanding accent etc. which impact creates a psychological pressure.

Akhtaruzzaman and Hoque (2011)two professors ofInternational Islamic University Malaysia in their article 'A Study on Cultural Adaptation of Bangladeshi Male Students at UIA, Malaysia' discussvarious cultural gaps among the Bangladeshi students.The researchers conducted this research through the interview. They mention some cultural gaps like food problem, homesickness, financial intricacy and language barrier. Through gross interview, some issues have been visible that Bangladeshi students communicate in English with everyone while English is not their mother tongue. Besides, six seasons are available in Bangladesh but it is absent in Malaysia. In terms of food, they use oily and very different from other countries. At the outset, students face problem to understand the class lecture. Pronunciation and accent is 
another problem when they communicated with other nationalities in Malaysia. Bangladeshi students are trying their level best to adjust to new environment.

Baier (2005) a researcher of Eastern Michigan University in his thesis paper titled 'International students: Culture shock and adaptation to the U.S. culture' discusses that international students are experiencing culture shock at a community college in the Midwestern United States. He compares students from the western and non-western background in this paper. Mix methodology namely questionnaire and interview have been used in this thesis paper. He points out that International students faced a variety of experiences when they came to the American life style. International students come from various language, culture, religious, political, economic, social, family backgrounds, and regions with different climate and topographical characteristics. All these aspects have shaped the students' personal lives; therefore, when coming to the USA these students realize that their backgrounds differ from the U.S. culture in many ways.

Belhadi and Ayad (2016/2017) two researchers of University of Tlemcen in their dissertation 'Culture Shock among International Students:A Case Study at The University of Tlemcen' say that International students come from various countries and regions like Africa and China to continue their higher education face cultural shocks. It is both qualitative and quantitative research. The key findings revealed that all international students experienced culture shock in both social and academic life.Academic cultural shock also appears there because of educational environment (teachers, classmates, and curriculum) which is mismatch according to his expectation. Language proficiency is another barrier for an academic cultural shock. He suggested some ways to cope with this problem. Effort should be come from both levels to minimize this problem.

Thomson, Rosenthal and Russell (2006), three professors of The University of Melbourne on their 'Cultural Stress among International Students at an Australian University' discuss that international student faces a complex challenge to undertake university or other educational courses. Such a problem becomes acute when home country culture is strikingly different from the host country culture.Survey questionnaire has been conducted to analyze this issue. They say that although students comment on cultural shock but their answer was not at an extreme level. Half of the students miss their family is expected indeed in the host country.

Xia (2009), an international communication specialist, discussed that the world became so closer by dint of advanced technology. This facilitated the people to come closer. People are entering a new environment and facing new values, new practice and ways of living.To reduce psychological pressure, one has to take some preparations before face new culture. But a full preparation can help the people to adjust with a newculture. People may try to different way to minimize the impact of culture shock on their psychology, but self-confident and optimistic may be the effective way. Winkelman (1994) presented that culture shock is a multifaceted experience that happens when someone in contact with a different culture. Someone affected physiologically and psychologically where numerous stressors exist. He suggested an individual plan is required to overcome this shock.

Guru, Siddiqui, Ahmed \& Khan (2012), four persons from UK and Pakistan in their 'Effects of cultural shock on foreign health care professionals: An analysis of key factors' discuss that foreign health care professional's face severe problem to settle in abroad. Some problems includeviolence at work, racial, low salaries, fight for survival, huge workload etc. Migrants' health professionals do not pay properly and even sometimes they are recommended to provide low salary. Family issues are also serious issues for migrants that can lead to cultural 
shock. Developed countries health sector are full of new technologies which demand an added skill among health professionals. Foreign health professionals do not have much exposure to the latest technologies and computer works. This takes time to learn and person gradually develop understanding because every country has their own system and procedures in their health care and initially getting along with those systems would be hard for aforeign healthcare worker who does not have such kind of exposure in their home country. They say that anyone could not get set procedure but they have to develop such procedure with the passage of time.

The kinds of literature discussed here various culture shocks and its psychological pressure on the students. When people away from his native country, they face new values, a new way of living. This pattern of research works is pertinent to the Bangladeshi students who face various cultural challenges in the new environment and striving to cope up with it. Still, no research is found particularly on Bangladeshi students who living in abroad and facing cultural shocks. This paper is dedicated to fulfilling this gap by investigating the causes of culture shocks in abroad.

\section{METHODOLOGY}

This study follows a quantitative research methodology where data have been collected from primary sources. The primary data has been collected from Bangladeshi students studying abroad. Under a convenient sampling method, we have taken nine different countries namely from USA, UK, China, India, Malaysia, Australia, Thailand and Norway. Using purposive sampling method, we have conducted a surveythrough Google doc. The questionnaire was designed by using five-point liker type questions to measure the culture shock. The questionnaire was developed by the researchers with the help of existing literatures. Finally, the questionnaire through Google doc has been collected by using Facebook groups and in person email. The questionnaire was sent to 60 respondents but 36 of them returned with an adequate answer. We also made a telephone conversation with the respondents to secure the validity and reliability of the data. To analyze the data, we have used IBM SPSS 20 (Statistical Package for the Social Sciences) as software and one-way ANOVA as a statistical tool. 
Table 1: Demographic Profile of the Respondents

\begin{tabular}{|c|c|c|}
\hline Criteria & Frequency (n) & Percentage (\%) \\
\hline \multicolumn{3}{|l|}{ Gender } \\
\hline Male & 26 & 72.2 \\
\hline Female & 10 & 27.8 \\
\hline \multicolumn{3}{|l|}{ Age distribution } \\
\hline $20-30$ & 21 & 58.3 \\
\hline $31-40$ & 13 & 36.1 \\
\hline $41-50$ & 02 & 5.6 \\
\hline \multicolumn{3}{|l|}{ Education } \\
\hline Graduate & 10 & 27.8 \\
\hline Post graduate & 15 & 41.7 \\
\hline $\mathrm{PhD}$ & 11 & 30.6 \\
\hline \multicolumn{3}{|l|}{ Region } \\
\hline America & 06 & 16.7 \\
\hline Australia & 06 & 16.7 \\
\hline Europe & 07 & 19.4 \\
\hline East Asia & 11 & 30.6 \\
\hline Middle East & 06 & 16.7 \\
\hline \multicolumn{3}{|l|}{ Duration of Living } \\
\hline Less than 1 year & 13 & 36.1 \\
\hline 1-3 years & 13 & 36.1 \\
\hline 4-6 years & 07 & 19.5 \\
\hline $6-10$ years & 03 & 8.3 \\
\hline
\end{tabular}

Source: Online Survey, 2018

\section{CONCEPTUAL FRAMEWORK}

\section{Culture:}

It is difficult to define culture but a culture is a system of ideas, beliefs, values, norms, knowledge, customs, tradition and technology shared by almost everyone in a particular society. Anyone expresses culture through dress, food, language, and various activities. It is an abstract thing. Culture exists in the minds or habits of the members of society. Culture is the shared ways of doing and thinking. According to Cambridge Dictionary Culture is the way of life, especially the general customs and beliefs, of a particular group of people at a particular time. Talcott Parsons says in Essays in Sociological Theory that "Culture...consists in those patterns relative to behavior and the products of human action which may be inherited, that is, passed on from generation to generation independently of the biological genes".

So we can that culture is the web of ways of living, behaviors, beliefs, customs, values, social institutions, aesthetic standards, and styles of communication which a group of people have developed to maintain its survival in a particular physical and human environment. Its pervasive binding force belongs to a group of people who identify themselves as "Us". Culture is a non-evaluative term, neither good nor bad.

\section{Cultural Shock:}

Culture shock is the feeling of unpleasant or uneasy that someone suffers when they come from to live in a country which is different from the origin. Anyone experiences this feeling when facing an unfamiliar culture, way of life, or set of attitudes. According to Marriam-Webster, Cultural Shock is a sense of confusion and uncertainty sometimes with feelings of anxiety that may affect people exposed to an alien culture or environment without adequate preparation. According to Cambridge Dictionary, cultural shock is a feeling of confusion felt by someone 
visiting a country or place that they do not know. Culture shock was conceptualized by Oberg in the mid-1950s and defined as the consequence of strain and anxiety resulting from contact with a new culture and the feelings of loss, confusion, and impotence, which are due to loss of accustomed cultural cues and social rules. Culture shock is a natural state of psychological and physical disorientation that can occur upon encountering a new environment and culture. Loss of social support networks, independence, and the ability to communicate combined with the differences and challenges of entering a new culture are all factors that contribute to feelings of culture shock.

Adler writes that "culture shock is primarily a set of emotional reactions to the loss of perceptual reinforcements from one's own culture, to new cultural stimuli which have little or no meaning, and to the misunderstanding of new and diverse experiences. It may encompass feelings of helplessness, irritability, and fears of being cheated, contaminated, injured or disregarded."

\section{Reliability test}

\section{DATA ANALYSIS AND DISCUSSION}

In order to determine if the survey questions were consistently giving reliable results, Cronbach's Alpha value for the overall measure and each scale is the widely used reliability measurement.

The commonly used threshold of $\alpha=0.70$ (Joshep, 2003) was employed to evaluate the scales. Here, after considering total 10 items, it is found that the value of Cronbach Alpha coefficient of internal consistency is 0.703 .

When theindividual scale items are not scaled the same, all scale items have to be standardized. In this situation we can use another Cronbach's alpha coefficient of internal consistencycalled "Standardized Item Alpha". As we have used two scale for different variables, we have found the "Standardized item Alpha" is equal to 0.690 which is also very close to 0.7 the threshold level which shows that the items are reliable.

\section{Language barriers in communication}

Hypothesis 1:

The null hypothesis is" Respondents haven't faced any language barrier among different countries."

The alternative hypothesis is "Respondents have faced language barrier among different countries."

Table 2: The one-way analysis of variance on differences in language barrier by countries

\begin{tabular}{|c|c|c|c|c|c|}
\hline & $\begin{array}{c}\text { Sum of } \\
\text { Squares }\end{array}$ & $\mathrm{df}$ & $\begin{array}{c}\text { Mean } \\
\text { Square }\end{array}$ & $\mathrm{F}$ & Sig. \\
\hline Between Groups & 43.050 & 13 & 3.312 & 5.222 & .000 \\
Within Groups & 13.950 & 22 & .634 & & \\
Total & 57.000 & 35 & & & \\
\hline
\end{tabular}

Here after using one-way ANOVA, F $(13,22)=5.22$, p-value $=.000$. The $p$-value has been found less than 0.05 . That means null hypothesis may be rejected at $5 \%$ level of significance. So, it can be concluded that students studying in different countries are facing language barrier. Language barrier- specific characteristics often influenced by different country may play a crucial role in this process. 
Descriptive analysis: A language is an important tool of correspondence. It is not the only meaning of sharing ideas and thoughts, but also helps to build relationships with others. It is an element of culture. Every country has its own languages to speak like Bangla is the mother tongue of Bangladeshi as the means of communication. Language barriers are the most common communication barriers which cause misunderstandings and misinterpretations among the people. Bangladeshi students are travelling in abroad to take higher education from various foreign universities and facing sorts of language barriers. If English is not the first language, one may find to miss familiar language which at home would have been part of the everyday environment. Language related barrier varies from country to country and problems have also various dimensions. The language barrier in English native countries is apprehending firstly accent and secondly quick delivery from the people that becomes somewhat tough to understand; especially problem is acute outside the campus when anyone needs to communicate with the locals. Communications other than English native countries are also difficult, as people most of the time usetheir local language. Local people use their local language as the means of communication.

\section{Striving to cope up with local food habits}

\section{Hypothesis 2:}

The null hypothesis is "Respondents haven't faced any problem with the new food habit of that country among region."

The alternative hypothesis is "Respondents have faced problem with the new food habit of that country among region."

Table 3: The one-way analysis of variance on facing problem for the new food habit by different regions

\begin{tabular}{|l|c|c|c|c|c|}
\hline & $\begin{array}{c}\text { Sum of } \\
\text { Squares }\end{array}$ & $\mathrm{df}$ & $\begin{array}{c}\text { Mean } \\
\text { Square }\end{array}$ & $\mathrm{F}$ & Sig. \\
\hline Between Groups & 16.267 & 4 & 4.067 & 3.202 & .026 \\
Within Groups & 39.372 & 31 & 1.270 & & \\
Total & 55.639 & 35 & & & \\
\hline
\end{tabular}

Here after using one-way ANOVA, F $(4,31)=3.202$, p-value $=.026$. The p-value has been found less than 0.05 . That means null hypothesis may be rejected at $5 \%$ level of significance. So, it can be concluded that students studying in different regions are facing problem with new food habit of that country. Food habit may be influenced by the location of that country where it is located.

Descriptive analysis: Bangladeshi students face the various culture food related-problem. Firstly, students seek such type of menu which they received in Bangladesh since long time but it is hardly found around them. Rice and fish are the main staple food of Bangladeshi people. The famous proverb "Mache-bhate bangali" translates as "Bengali by fish and rice." Suitable food items are hardly found in their surroundings. Secondly, finding halal food is another big challenge for the students. Halal food means such types of food which Islam permits to receive. On the other hand, Islam does not permit some food items (called haram) which may be permitted by other religion or culture and also available around them. Availability of haram food made them worried to survive smoothly. Sometimes they have to go far distance to collect halal food items. Thirdly, some students cook themselves willingly to avoid haram food item and to add availability of spicy. Fourth, less use of spicy within the curry is another problem for the students. Generally, Bangladeshis use different type of spicy to cook curry but they do not get this taste of local spice in abroad and they really crave for it. In addition to they rely on Indian grocery shops to get local items in many nations like UK, USA, and Australia. Fifth, 
someone feels uneasy to use chopstick at some stage in taking food in China. It was new system for Bangladeshi students to adjust with it.

Acceptance in the surroundings

Figure 1: Acceptance by surrounding

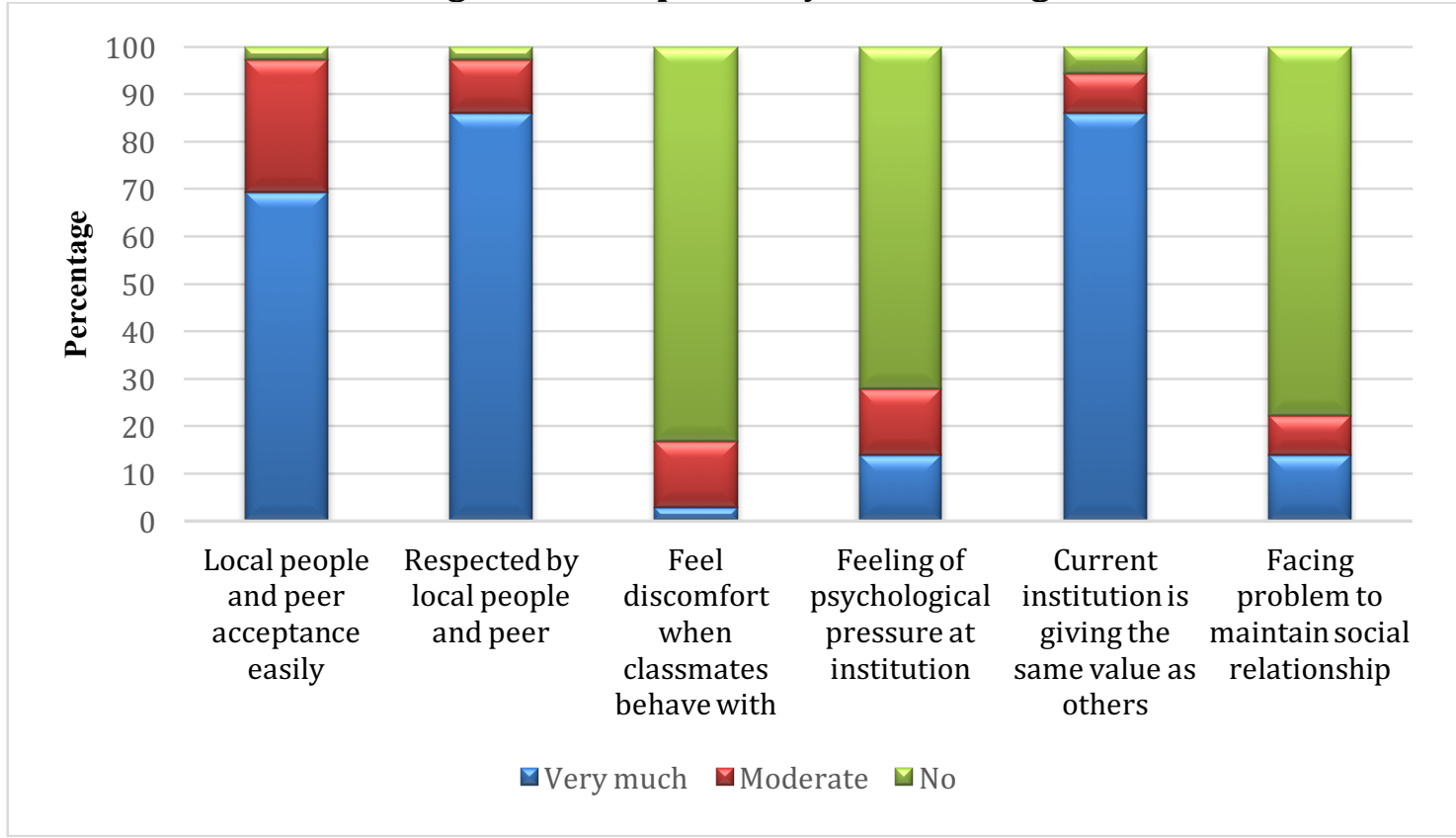

Source : Online Survey, 2018

It is very common to rely on society to live happily. It is expected to get respect, acceptance, and value, good behavior from the circle (inside the campus and outside the campus) for adjustment in a hurry. Most of the respondents gave positive consent that local people accept and respect them, classmates behave very well, manner is very friendly and institution give equal values that help them to maintain social kinship with their surroundings. Moreover, very few students got psychological pressure at their institutions in terms of getting benefits, value and respects. Very few respondents cannot maintain social relationship with locals because of religious and perspective differences.

\section{Environmental impediment in Inhabitants}

Hypothesis 3:

The null hypothesis is "Respondents haven't faced any problem with the new weather among different regions."

The alternative hypothesis is "Respondents have faced problem with the new weather among different regions."

Table 4: The one-way analysis of variance on facing problem for the new food habit by different regions

\begin{tabular}{|l|c|c|c|c|c|}
\hline & $\begin{array}{c}\text { Sum of } \\
\text { Squares }\end{array}$ & $\mathrm{df}$ & $\begin{array}{c}\text { Mean } \\
\text { Square }\end{array}$ & $\mathrm{F}$ & Sig. \\
\hline Between Groups & 29.917 & 13 & 2.301 & 1.542 & .179 \\
Within Groups & 32.833 & 22 & 1.492 & & \\
Total & 62.750 & 35 & & & \\
\hline
\end{tabular}


Here after using one-way ANOVA, F $(13,22)=1.542$, p-value $=.179$. The $p$-value has been found greater than 0.05 . That means null hypothesis may be rejected at $5 \%$ level of significance. So, it can be concluded that students studying in different regions are not facing significant problem with new weather.

Descriptive analysis:Bangladesh has a subtropical monsoon climate characterized by wide seasonal variations in rainfall, high temperatures and humidity. Here are six seasons while the spring is called the king of seasons. The climate sometimes is very pleasant that inspires people to take morning and evening walks (Banglapedia). Climate is some place exceptionally hot and some place extremely chilly. Middle East temperature is very hot while Japan or Norway temperature is very cold. Somewhere like UAE and KSA they face scorching hit while somewhere heavy dress up is mandatory to get rid of cold. Some Bangladeshi students are struggling with such varied temperature to survive while some others tried to cope up with it. In cold country, Bangladeshi students have to put on heavy dress-up to protect them from such cold. Someone feels uneasy because of wind.

\section{Problem due to diversity of clothing}

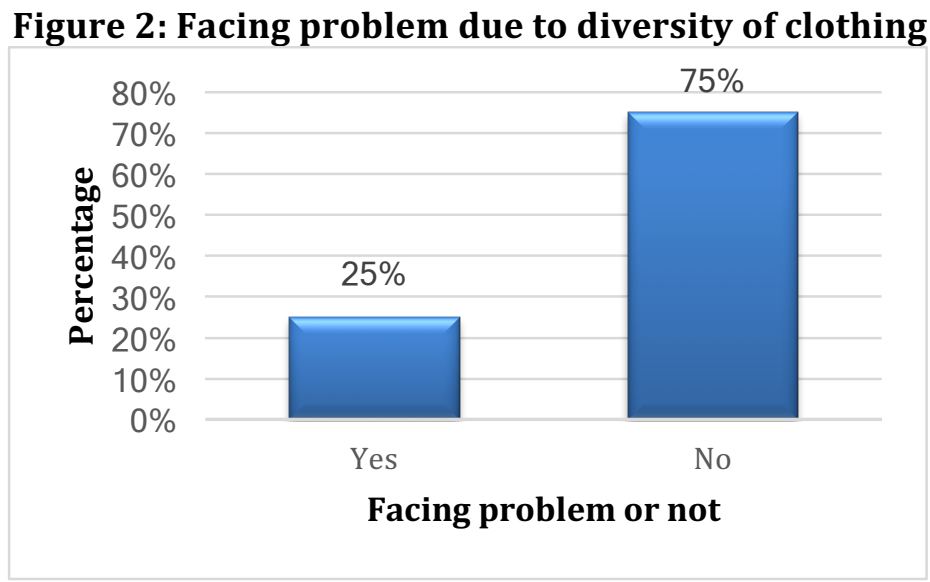

Source: Online Survey, 2018

It was found from the study that $75 \%$ of the respondents do not face any problem and $25 \%$ face the problem.Some respondents used to put on scarf and veil as the norms of religion, however the country does not encourage to wear such dress up. Someone does not like to wear local dress because they feel discomfort. In addition, to wear many dresses in the cold main country and to wear light dresses in the warmer country also have difficulties for someone.

\section{Tending for familiar something}

A large portion of the respondents opined, in reply to this inquiry whether they miss anything in abroad or not, they addressed numerous things missingtheir life.In spite of the fact that they discovered bunches of companions around them, they feel still alone.There is nothing in the surroundings that seems to be everything. In the host nation, they miss family, guardians, companions, friends and relatives, society and neighbors.They feel dejectionwhen they remember eventful memories in school, college, university. Tattling with companions throughout their life circle is the most paramount occasion. 


\section{Strain of adaptation with new culture}

Figure 3:Strain of adaptation with new culture

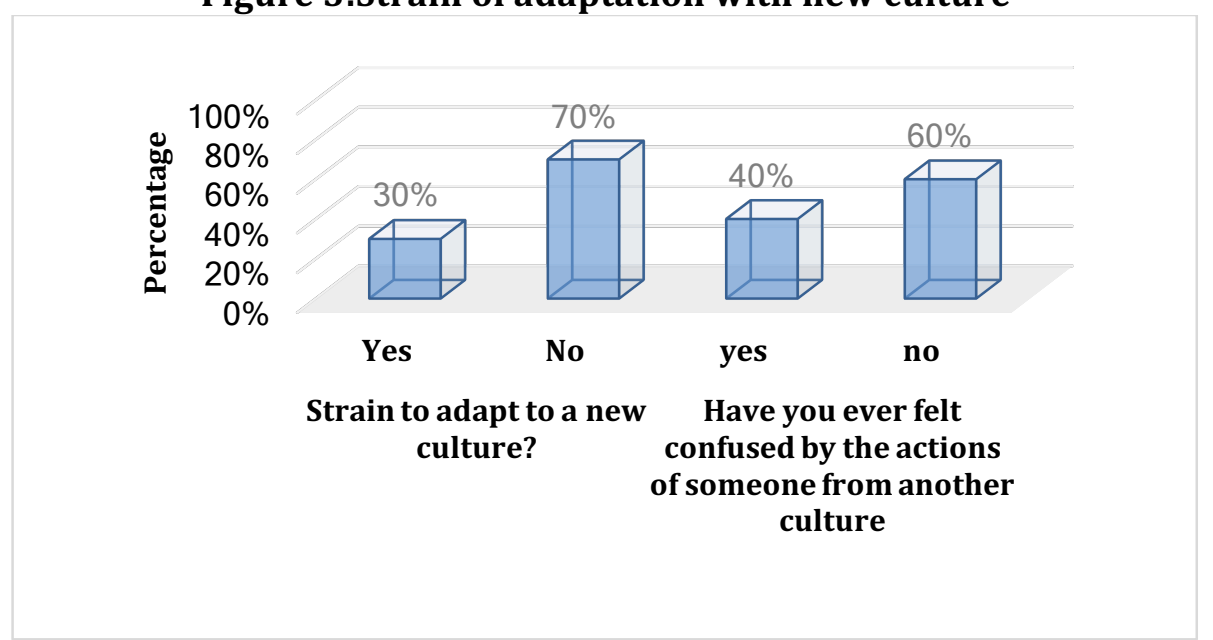

Source: Online Survey, 2018

$30 \%$ respondents in this survey opined that they have strain to adapt and $40 \%$ respondents felt confused by the actions of someone to the new culture when they have gone for study. Every country possesses its own characteristics in food habit, culture, study style, customs, social lifestyle, communication style and so on that may be different from ours. Some student does not feel any strain or confused while some of them feel uneasy. It has known through a telephone interview that when someone communicates with others, approaching style differs due to ages. A boy when meet with senior will touch nose together, young boys will touch neck to neck and aged person touch neck to neck and kiss on the forehead. Some respondents have identified religious aspects made the differences to live without strain and confusion. Some of them have mentioned that their educational institutions are opened even on Eid Day that is another cause of strain.

\section{Gathering experiences from the new culture}

Although they are living in abroad for study, they are learning many things in their life from the new environment. To the question of the biggest difference between before and after living in abroad, respondents delivered different opinions. The respondents have mentioned some remarkable learning issues. They have stated in the telephone conversation and survey that how to respect all classes of people, how to follow honesty, ability to adjust with new culture, knowing about the foreign education system, how to be self-dependent, increasing thinking power, and so on. Bangladeshi students are very much pleasured owing to learning new issues regularly.

\section{CONCLUSION AND RECOMMENDATIONS}

Bangladeshi students face different types of culture shocks in the host country. The feel of loneliness, miss their much-known persons, places. Such problems come following they face language barrier, food barrier, weather mismatch and so on. Native English speakers delivered English quickly and an accent is sometimes also obscure that creates misunderstanding. There is inadequate Bangladeshi food and even at times, such foods are also not available around them.

Finally, this study proposes the following recommendations:

- The students should practice English accent, listening and speaking earlier to enroll to the foreign university. 
- They should take available news how they could manage Bangladeshi foods in the host country. As everything is available to the internet, so adjustment news may be taken earlier to depart. They may also take help from anyone who are enrolled in that place or near to it. Bangladeshi embassy may be good choice in this context to receive assistance.

- Go through foreign culture earlier to depart so that one can decide how to adjust in the host country.

- Adjustment mentality should keep in new environment, as some problems may arise in the new culture.

\section{References}

Aisha Naeem, A. B. (2015): Culture Shock and Its effects on Expatriates. Global Advanced Research Journal of Management and Business Studies, 248-258.

Adler, P.S. 1975. The transitional experience: An alternative view of culture shock. Journal of Humanistic Psychology 15 4, pp. 13-23.

Alamgir, M. (2018, 01 14). http://www.newagebd.net. Retrieved 04 16, 2018, from http://www.newagebd.net: http://www.newagebd.net/article/32507/outflux-of-students-doubles-in-10-years

Baier, S. T. (2005). International students: culture shock and adaptation to the u.s. culture. Michigan: Eastern Michigan University.

BANGALORE. (2013, 01 19). https://timesofindia.indiatimes.com/india. Retrieved 12 06, 2017, from https://timesofindia.indiatimes.com/india: https://timesofindia.indiatimes.com/india/Bangalore-studentcommits-suicide-in-Germany/articleshow/18083360.cms

Erika Zoeller Veras, D. B. (2011). Cultural Differences Between Countries: The Brazilian and the Chinese Ways of Doing Business. Journal on Innovation and Sustainability, 77-84.

Garry Thomson, D. R. (2006). Cultural stress among international students at an Australian university . Melbourne: 2006.

Farah Belhadi, S. A. (2017). Culture Shock Among International Students:A Case Study at The University of Tlemcen. PEOPLE'S DEMOCRATIC REPUBLIC OF ALGERIA: University of Tlemcen.

Jha, L. K. (2017, 11 13). 7,143 Bangladeshi students in the US for higher education. Dhaka, Dhaka, Bangladesh.

Hasnat, M. A. (2018, 01 28). https://www.dhakatribune.com. Retrieved 05 09, 2018, from

https://www.dhakatribune.com: https://www.dhakatribune.com/opinion/special/2018/01/28/student-exodusdoubles-decade

Md. Akhtaruzzaman, M. H. (2011). A Study on Cultural Adaptation of Bangladeshi Male Students at UIA, Malaysia. American Journal of Sociological Research, 1-8.

Niekerk, A. v. (2012, 1128$) .40 \%$ of foreign students in the US have no close friends on campus: The culture shock of loneliness. Retrieved 07 25, 2018, from https://qz.com/31376/40-of-foreign-students-in-the-us-have-no-closefriends-on-campus-the-culture-shock-of-loneliness/: https://qz.com/31376/40-of-foreign-students-in-the-ushave-no-close-friends-on-campus-the-culture-shock-of-loneliness/

Sarwal, A. (2017, 03 16). Overseas qualified health professionals frustrated by Australia's registration process, APC working on reforms. Retrieved 0424,2018 , from Overseas qualified health professionals frustrated by Australia's registration process, APC working on reforms:

https://www.sbs.com.au/yourlanguage/hindi/en/audiotrack/overseas-qualified-health-professionalsfrustrated-australias-registration-process-apc

Tawhid, B. (2017, 06 17). https://www.thedailystar.net. Retrieved 02 02, 2018, from https://www.thedailystar.net: https://www.thedailystar.net/next-step/features/why-bangladeshi-studentsshould-consider-studying-japan-1420918 